\title{
ANALISIS PENGGUNAAN FAKTOR-FAKTOR PRODUKSI PADA USAHATANI JANGGELAN DI KECAMATAN KARANGTENGAH KABUPATEN WONOGIRI
}

\author{
Jesica Theresia $^{1)}$, Erlyna Wida Riptanti ${ }^{1}$, Susi Wuri Ani ${ }^{1)}$ \\ Program Studi Agribisnis, Fakultas Pertanian, Universitas Sebelas Maret \\ Email: jesicatheresia25@gmail.com
}

\begin{abstract}
This research was aimed to analyze the amount of the costs, the revenue and the income of black grass jelly farming, and analyze the use of factors which influence the production of black grass jelly in Karangtengah Sub-District, Wonogiri District. The location of the research was determined by purposive sampling method. The Village that used on this research was selected bypurposive sampling method. The samples in this research were 40 respondents selected by using proportional random sampling method. The data used in this research was primary and secondary data. The data analysis that usedon this research were:(1) the analysis of the costs, the reception and the income of the farming, (2) the analysis of production function by Cobb-Douglas.The reseach result, based on the analysis of the black grass jelly farming with the land area of 0,37 $\mathrm{Ha}$ explained the cost of establishing the farming was $R p$ 4.425.482,50/PT, the reception of the farming was Rp19.930.000,00/PT and the income of the farming was $R p$ 15.504.517,50/PT. The equation function by Cobb-Douglas was : $\operatorname{Ln} \hat{Y}=7,224+0,767 \ln X 1-0,162 \ln X 2+0,107 \ln X 3+0,001 \ln X 4+$ $0,317 \ln X 5+0,007 \ln X 6$. The result of regression showed that production factors such as; land area, the number of seeds, urea fertilizer, phonska fertilizer, manure, and the labors had the real impact toward the production of black grass jelly.Individually, the production factors such as; urea fertilizer, phonska fertilizer, and the labors did not have the real impact on production of black grass jelly.
\end{abstract}

Keywords : Black Jelly Grass, Cobb-Douglas, Farming, Production Factors

\section{PENDAHULUAN}

Indonesia merupakan negara berkembang dengan pertanian sebagai sektor utama. Penyerapan tenaga kerja pada sektor adalah paling besar. Dilihat dari data Badan Pusat Statistik (2013) yaitu 38,97 juta orang (33,99 persen) dari 114,62 juta orang angkatan kerja Indonesia. Sub sektor perkebunan sebagai bagian dari sektor pertanian tercatat memiliki pertumbuhan yang pesat, baik luasan areal maupun produksi. Menurut Wulandari (2015) sub sektor perkebunan mempunyai peranan yang penting dan strategis dalam perekonomian. Peranan penting subsektor perkebunan yaitu meningkatkan kemakmuran dan kesejahteraan rakyat, penerimaan devisa negara melalui ekspor, dan penyediaan lapangan kerja.

Janggelan merupakan salah satu komoditas tanaman perkebunan yang sangat potensial untuk dikembangkan. Berdasarkan data BPS Jawa Tengah (2015), saat ini budidaya janggelan baru dibudidayakan oleh petani yang berada di Kabupaten Wonogiri. Berdasarkan Tabel 1, diketahui bahwa laju pertumbuhan rata-rata produksi janggelan di Kabupaten Wonogiri dari tahun 2009 hingga tahun 2012 mengalami penurunan. Pada tahun 2013 sampai tahun 2014 produktivitas janggelan kembali mengalami kenaikan.

Kecamatan Karangtengah merupakan kecamatan dengan tingkat produksi paling tinggi di Kabupaten Wonogiri yaitu sebesar 2.234 ton. Kecamatan Karangtengah merupakan salah satu kecamatan yang terletak di bagian tenggara dari Kabupaten Wonogiri. Kecamatan Karangtengah memiliki ketinggian 750 mdpl, sehingga memiliki iklim yang cocok untuk budidaya janggelan. Hasil produksi janggelan di Kecamatan Karangtengah sangat tinggi dan mampu menjadi sentra ekspor tanaman janggelan di Indonesia.

Menurut Kadarsan (1992), untuk memperoleh pendapatan yang memuaskan, seorang petani perlu memiliki dan atau menguasai faktor produksi yang diperlukan, dengan jumlah yang semaksimal mungkin dengan kombinasi yang setepat mungkin. Seringkali petani dihadapkan pada 
permasalahan bagaimana mengkombinasikan faktor-faktor produksi yang dimilikinya secara tepat dan efisien untuk menghasilkan produksi maksimal sehingga keuntungan tertinggi dapat tercapai.

Masalah terkait dengan janggelan adalah produktivitas yang belum optimal. Permintaan akan janggelan produksi Indonesia di pasar luar negeri terbilang tinggi. Berdasarkan sebuah artikel yang dibuat oleh Media Indonesia pada tanggal 07 Februari 2013 permintaan jangelan kering ke Kabupaten Wonogiri sebesar 25.000 ton. Namun petani Wonogiri hanya dapat memenuhi permintaan pasar sebesar 5425 ton per tahun janggelan kering. Ini berarti terdapat devisit produksi dengan permintaan yang cukup tinggi. Devisit produksi ini terjadi akibat dari produksi janggelan yang berfluktuatif di Kecamatan Karangtengah seperti yang terlihat pada Tabel
1 produktivitas janggelan mengalami fluktuasi produksi pada luas lahan yang sama.

Bertitik tolak dari hal tersebut, maka dibuat rumusan masalah yang akan dikaji dalam penelitian ini adalah berapa besarnya biaya produksi, penerimaan dan pendapatan usahatani janggelan di Kecamatan Karangtengah Kabupaten Wonogiri dan faktor-faktor produksi apa saja yang berpengaruh terhadap jumlah produksi pada usahatani janggelan di Kecamatan Karangtengah Kabupaten Wonogiri.

Tujuan dari penelitian ini adalah untuk menganalisis biaya produksi, penerimaan dan pendapatan usahatani janggelan di Kecamatan Karangtengah Kabupaten Wonogiri dan mengetahui faktor-faktor produksi apa saja yang berpengaruh terhadap jumlah produksi pada usahatani janggelan di Kecamatan Karangtengah Kabupaten Wonogiri.

Tabel 1. Luas panen dan produktivitas janggelan di Kabupaten Wonogiri tahun 2009-2014

\begin{tabular}{cccc}
\hline Tahun & $\begin{array}{c}\text { Luas Lahan } \\
\text { (ha) }\end{array}$ & $\begin{array}{c}\text { Produksi } \\
\text { (ton) }\end{array}$ & $\begin{array}{c}\text { Produktivitas } \\
\text { (ton/ha) }\end{array}$ \\
\hline 2009 & 1.346 & 5.399 & 4,005 \\
2010 & 1.346 & 5.323 & 3,949 \\
2011 & 1.348 & 5.323 & 3,949 \\
2012 & 1.348 & 5.331 & 3,955 \\
2013 & 1.348 & 5.399 & 4,005 \\
2014 & 1.348 & 5.425 & 4,024 \\
\hline
\end{tabular}

Sumber : BPS Wonogiri diolah Dinas Kehutanan dan Perkebunan Kabupaten Wonogiri Tahun 2015.

Tabel 2. Luas areal dan produksi tanaman janggelan menurut Kecamatan di Kabupaten Wonogiri tahun 2014

\begin{tabular}{clrrr}
\hline No & \multicolumn{1}{c}{ Kecamatan } & $\begin{array}{c}\text { Luas Lahan } \\
(\mathrm{Ha})\end{array}$ & $\begin{array}{c}\text { Produksi kering } \\
\text { (ton) }\end{array}$ & $\begin{array}{c}\text { Produktivitas } \\
\text { (ton/ha) }\end{array}$ \\
\hline 1 & Selogiri & 5 & 31 & 6,200 \\
2 & Kismantoro & 130 & 727 & 5,592 \\
3 & Slogohimo & 63 & 345 & 5,476 \\
4 & Puh Pelem & 38 & 201 & 5,289 \\
5 & Jatipuro & 55 & 259 & 4,709 \\
6 & Batuwarno & 71 & 295 & 4,155 \\
7 & Karangtengah & 573 & 2038 & 3,557 \\
8 & Tirtomoyo & 205 & 695 & 3,390 \\
9 & Bulukerto & 160 & 604 & 3,775 \\
10 & Girimarto & 48 & 128 & 2,667 \\
\hline Jumlah & 1.348 & 5.523 & 4,097 \\
\hline
\end{tabular}

Sumber : BPS Wonogiri diolah Dinas Kehutanan dan Perkebunan Kabupaten Wonogiri tahun 2015.

\section{METODE PENELITIAN}

Metode dasar penelitian dalam penelitian ini adalah metode deskriptif analisisSurakhmad (1994). Teknik penelitian yang digunakan dalam penelitian ini adalah teknik penelitian survei (Singarimbun, 1995).

Metode penentuan lokasi penelitian dengan menggunakan metode purposive sampling. Pemilihan desa penelitian dilakukan dengan purposive (sengaja) dengan alasan 
kecamatan Karangtengah merupakan kecamatan yang memiliki luas lahan garapan dan jumlah produksi usahatani janggelan paling tinggi diantara 10 kecamatan yang ada di Kabupaten Wonogiri. Penentuan jumlah sampel dalam penelitian ini adalah 40 responden dengan menggunakan metode proporsional random sampling untuk memenuhi jumlah minimal responden data parametrik statistik dengan sebaran normal yakni sebanyak 30 responden (Singarimbun, 1995). Data yang digunakan adalah primer dan sekunder.

Analisis biaya, penerimaan dan pendapatan dengan rumus sebagai berikut:

$$
\begin{aligned}
\mathrm{PrU}= & (\mathrm{Py} \times \mathrm{Y}) \\
\mathrm{PdU}= & \text { PrU }-(\text { Biaya alat-alat luar }+\mathrm{Upah} \\
& \text { tenaga kerja keluarga })
\end{aligned}
$$

Keterangan :

$\mathrm{PrU}$ : Penerimaan usahatani (Rp/Ha/ MT)

Py : Harga hasil produksi usahatani $(\mathrm{Rp} / \mathrm{Ha}$ /MT)

$\mathrm{Y}$ : Hasil produksi usahatani $(\mathrm{Kg} / \mathrm{Ha} / \mathrm{MT})$

PdU : Pendapatan usahatani (Rp/Ha/ MT)

Analisis pengaruh penggunaan faktorfaktor produksi terhadap hasil produksi pada usahatani janggelan dilakukan dengan menggunakan fungsi produksi Cobb-Douglas. Secara matematik, fungsi Cobb-Douglas dapat dituliskan sebagai berikut :

$\mathrm{Y}=\mathrm{aX} 1^{\mathrm{b} 1} \times 2^{\mathrm{b} 2} \mathrm{X} 3^{\mathrm{b} 3} \times 4^{\mathrm{b} 4} \times 5^{\mathrm{b} 5} \times 6^{\mathrm{b} 6} \mathrm{e}^{\mathrm{u}}$

Dengan mentransformasikan dari fungsi Cobb-Douglas ke dalam bentuk linear logaritmik, maka model fungsi produksi tersebut dapat ditulis sebagai berikut:

$\mathrm{Ln} Y=\ln \mathrm{a}+\mathrm{b}_{1} \ln \mathrm{X} 1+\mathrm{b}_{2} \ln \mathrm{X} 2+\mathrm{b}_{3} \ln \mathrm{X} 3+$ $\mathrm{b}_{4} \ln \mathrm{X} 4+\mathrm{b}_{5} \ln \mathrm{X} 5+\mathrm{b}_{6} \ln \mathrm{X} 6+\mathrm{e}$

Dimana : $\mathrm{Y}=$ Hasil produksi janggelan $(\mathrm{Kg})$; $\mathrm{X} 1=$ Luas lahan yang digarap (Ha) ; $\mathrm{X} 2=$ Bibit (Batang) ; X3 = Pupuk urea (Kg) ; X4 = Pupuk phonska $(\mathrm{Kg}) ; \mathrm{X} 5=$ Pupuk kandang $(\mathrm{Kg}) ; \mathrm{X} 6=$ Tenaga kerja $(\mathrm{HKP}) ; \mathrm{a}$ =Konstanta, intersep, besaran parameter ; bi = Koefisien parameter penduga dimana $\mathrm{i}=1,2,3, \ldots . \mathrm{n} ; \mathrm{e}^{\mathrm{u}}=$ Error term

Untuk mengkaji apakah faktor-faktor produksi yang digunakan secara bersama-sama berpengaruh terhadap produksi janggelan digunakan Uji F (F-test). Pengaruh dari masing-masing faktor produksi terhadap hasil produksi digunakan uji keberartian koefisien regresi dengan uji t.

\section{HASIL DAN PEMBAHASAN}

Kecamatan Karangtengah merupakan salah satu Kecamatan di Kabupaten Wonogiri dengan letak astronomis $7^{\circ} 32^{\prime}-8^{\circ} 15^{\prime}$ Lintang Selatan dan $110^{\circ} 41^{\prime}-111^{\circ} 18^{\prime}$ Bujur Timur. Luas wilayah Kecamatan Karangtengah 8.596 ha atau $6.607 \mathrm{~km}^{2}$. Kecamatan Karangtengah dibagi menjadi 5 desa yakni Desa Purwoharjo, Desa Temboro, Desa Ngambarsari, Desa Karangtengah dan Desa Jeblogan. Kondisi topografi Kecamatan Karangtengah mendukung untuk kegiatan budidaya janggelan yang dapat tumbuh subur pada ketinggian 150-1.800 mdpl. Luas wilayah Kecamatan Karangtengah 8.596,00 Ha. Penggunaan tanah di Kecamatan Karangtengah $51 \%$ merupakan tanah tegalan, $18 \%$ berupa bangunan dan pekarangan, Sawah $7 \%$, dan $23 \%$ Hutan Negara.

Berdasarkan Tabel 3 dapat diketahui bahwa petani rata-rata berusia 16-60 tahun yang masih termasuk dalam usia produktif. Usia produktif memungkinkan petani untuk dapat mengelola usahataninya dengan baik. Rata-rata pendidikan formal yang ditempuh petani adalah lulus SMP. Rata-rata jumlah anggota keluarga adalah tiga orang dan yang aktif usahatani adalah 2 orang. Rata-rata luas lahan garapan petani ialah 0,37 $\mathrm{Ha}$.

\section{Analisis Usahatani Janggelan}

1. Biaya Total (TC) Usahatani Janggelan

a. Biaya Sarana Produksi

Besarnya biaya pembelian sarana produksi yang berupa bibit, pupuk urea,pupuk phonska dan pupuk kandang disajikan pada Tabel 4. Biaya terbesar adalah pupuk kandang, karena pada usahatani janggelan jumlah pupuk kandang yang butuhkan ialah 6 ton/MT. Sedangkan jumlah bibit merupakan rata-rata jumlah bibit yang dibeli petani, yang kemudian bibit tersebut akan disemai atau diperbanyak melalui stek batang.

b. Biaya Tenaga Kerja

Berdasarkan Tabel 5. diketahui rata-rata biaya untuk membayar upah tenaga kerja sebesar Rp. 3.096.250/MT. Biaya upah untuk tenaga kerja dalam maupun luar dihitung dengan besarnya upah tenaga kerja luar yaitu sebesar Rp. 50.000 
c. Biaya Lain-Lain

Berdasarkan Tabel 6 Disajikan besarnya biaya lain-lain usahatani janggelan yang berupa transportasi, pajak dan penyusutan. Biaya transportasi yang dimaksud ialah sewa pick up atau biaya bahan bakar kendaraan yang digunakan untuk mengangkut hasil panen.

Dari ketiga biaya tersebut maka biaya total (TC) pada usahatani janggelan di Kabupaten Janggelan ditampilkan pada Tabel 7.

2. Penerimaan (TR) Usahatani Janggelan

Penerimaan (TR) usahatani janggelan dapat diperoleh dengan mengalikan produksi total (Y) dengan harga produk (Py). Total produksi daun janggelan kering 420,58 Kg dan batang janggelan kering 1257,81 dengan harga dikalikan harga yang berlaku pada sat penelitian, maka diperoleh rata-rata penerimaan sebesar $\mathrm{Rp}$ 19.930.000,00.

3. Pendapatan Usahatani Janggelan

Pendapatan usahatani janggelan diperoleh dari selisih antara penerimaan (TR) dengan biaya mengusahakan. Berdasarkan Tabel 9 besarnya pendapatan yang diterima petani untuk satu musim tanam dengan luas lahan 0,37 Ha sebesar Rp15.504.517,50.

Tabel 4. Rata-rata biaya sarana produksi pada usahatani janggelan MT Juni 2015-Mei 2016 di Kecamatan Karangtengah

\begin{tabular}{clrrrrrr}
\hline \multirow{2}{*}{ No. } & \multirow{2}{*}{ Sarana Produksi } & \multicolumn{2}{c}{ Fisik $(\mathrm{Kg})$} & \multirow{2}{*}{ Harga } & \multicolumn{2}{c}{ Biaya (Rp) } \\
\cline { 2 - 3 } (Rp) & Per UT & Per Ha & Per UT & \multicolumn{1}{c}{ Per Ha } \\
\hline 1 & Bibit & 169,50 & 461,68 & 2000 & $169.500,00$ & $461.695,61$ \\
2 & Pupuk urea & 115,26 & 313,98 & 2700 & $311.242,50$ & $847.783,50$ \\
3 & Pupuk phonska & 74,52 & 202,98 & 3000 & $223.575,00$ & $608.988,76$ \\
4 & Pupuk kandang & $2.359,50$ & $6.426,68$ & 200 & $471.900,00$ & $1.285 .393,00$ \\
\hline & Jumlah & & & & $1.178 .217,50$ & $3.203 .860,87$ \\
\hline
\end{tabular}

Sumber : Analisis data primer.

Tabel 5. Rata-rata biaya tenaga kerja pada usahatani janggelan MT Juni 2015-Mei 2016 di Kecamatan Karangtengah

\begin{tabular}{clcc}
\hline \multirow{2}{*}{ No. Peralatan } & & \multicolumn{2}{c}{ Biaya (Rp) } \\
\cline { 3 - 4 } & & Per Usahatani & Per Ha \\
\hline 1 & Pengolahan lahan & 306.250 & 834.185 \\
2 & Pembibitan & 206.250 & 561.798 \\
3 & Penanaman & 233.750 & 636.704 \\
4 & Pemupukan & 143.750 & 391.556 \\
5 & Penyiangan & 157.500 & 429.009 \\
6 & Pemanenan & 966.250 & 2.631 .937 \\
7 & Pengeringan & 1.082 .500 & 2.948 .587 \\
\hline & Jumlah & 3.096 .250 & 8.433 .776 \\
\hline
\end{tabular}

Sumber: Analisis data primer.

Tabel 6. Rata-rata biaya lain-lain pada usahatani janggelan MT Juni 2015-Mei 2016 di Kecamatan Karangtengah

\begin{tabular}{clrr}
\hline \multirow{2}{*}{ No. } & & \multicolumn{2}{c}{ Biaya (Rp) } \\
\cline { 3 - 4 } & & Per Usahatani & Per Ha \\
\hline 1 & Transportasi & $40.700,00$ & $110.861,42$ \\
2 & Pajak & $22.265,00$ & $60.646,91$ \\
3 & Penyusutan & $88.050,00$ & $239.837,00$ \\
\hline & Jumlah & $151.015,00$ & $411.345,33$ \\
\hline
\end{tabular}

Sumber : Analisis data primer. 
Tabel 7. Rata-rata biaya mengusahakan pada usahatani janggelan MT Juni 2015-Mei 2016 di Kecamatan Karangtengah

\begin{tabular}{llrrr}
\hline \multirow{2}{*}{ No. } & \multirow{2}{*}{ Biaya Mengusahakan } & \multicolumn{2}{c}{ Biaya (Rp) } & \multirow{2}{*}{ \%) } \\
\cline { 3 - 4 } & & Per Usahatani & \multicolumn{1}{c}{ Per Ha } & \\
\hline 1 & Biaya Sarana Produksi & $1.178 .217,50$ & $3.203 .860,87$ & 26,6 \\
2 & Biaya Tenaga Kerja & $3.096 .250,00$ & $8.433 .776,00$ & 69,9 \\
3 & Biaya Lain-lain & $151.015,00$ & $411.345,33$ & 3,5 \\
\hline & Jumlah & $4.425 .482,50$ & $12.048 .982,20$ & 100 \\
\hline
\end{tabular}

Sumber : Analisis data primer.

Tabel 8. Rata-rata penerimaan pada usahatani janggelan MT Juni 2015-Mei 2016 di Kecamatan Karangtengah

\begin{tabular}{rlllllllll}
\hline No & Keterangan & \multicolumn{2}{l}{ Per Usahatani } & & & \multicolumn{3}{c}{ Per Hektar } \\
\cline { 2 - 9 } & & Panen 1 & \multicolumn{3}{c}{ Panen 2 } & & Panen 1 & & Panen 2 \\
\hline & & Batang & Daun & Batang & Daun & Batang & Daun & Batang & Daun \\
& Kering & Kering & Kering & Kering & Kering & Kering & Kering & Kering \\
\hline 1 & $\begin{array}{l}\text { Produksi } \\
\text { Kg) }\end{array}$ & 553,98 & 185,53 & 703,83 & 235,05 & 1.509 & 505,35 & $1.917,13$ & 640,25 \\
2 & $\begin{array}{l}\text { Harga } \\
\text { Produksi } \\
\text { (Rp/kg) }\end{array}$ & 7.000 & 25.000 & 8.000 & 25.000 & 7.000 & 25.000 & 8.000 & 25.000 \\
3 & $\begin{array}{l}\text { Penerimaan } \\
\text { (Rp) }\end{array}$ & 3.877 .860 & 4.638 .250 & 5.631 .440 & 5.876 .250 & 10.563 .000 & 12.633 .750 & 15.337 .040 & 16.006 .250 \\
\hline
\end{tabular}

Sumber : Analisis data primer.

Tabel 9. Rata-rata pendapatan pada usahatani janggelan MT Juni 2015-Mei 2016 di Kecamatan Karangtengah

\begin{tabular}{clcc}
\hline No. & \multicolumn{1}{c}{ Keterangan } & Per Usahatani & Per Hektar \\
\hline 1 & Penerimaan (TR) & $19.930 .000,00$ & $54.345 .000,00$ \\
2 & $\begin{array}{l}\text { Biaya Total (TC) } \\
\text { Biaya Mengusahakan }\end{array}$ & $4.425 .482,50$ & $12.048 .982,20$ \\
\hline & Pendapatan (Pd) & $15.504 .517,50$ & $42.296 .017,80$ \\
\hline
\end{tabular}

Sumber : Analisis data primer.

\section{Analisis Regresi Fungsi Produksi Cobb- Douglas}

Hubungan antara faktor-faktor produksi dengan hasil produksi janggelan dapat diketahui dengan menggunakan model fungsi produksi Cobb-Douglas. Hasil dari analisis yang telah dilakukan merupakan model fungsi produksi janggelan di Kecamatan Karangtengah Kabupaten Wonogiri.

Hasil dari analisis data yang telah dilakukan menghasilkan model sebagai berikut :

\section{$\operatorname{Ln} \widehat{Y}=7,224+0,767 \ln X 1-0,162 \ln X 2+$ 0,107 ln $\mathrm{X3}+0,001$ ln $\mathrm{X} 4+$ $0,317 \ln X 5+0,007 \ln X 6$}

Keterangan :

Y : Produksi janggelan $(\mathrm{Kg})$

Ln X1 : Luas lahan yang digarap (Ha)

Ln X2 : Bibit (Batang)

Ln X3 : Pupuk urea $(\mathrm{Kg})$

Ln X4 : Pupuk phonska (Kg)
Ln X5 : Pupuk kandang $(\mathrm{Kg})$

Ln X6 : Tenaga kerja (HKP)

a. Uji Determinasi

Nilai adjusted $\mathrm{R}^{2}$ dari hasil penelitian yaitu 0,995 artinya $99,5 \%$ produksi janggelan dipengaruhi oleh faktor produksi yang berupa luas lahan garapan, jumlah bibit, pupuk urea, pupuk phonska, pupuk kandang dan tenaga kerja. Sisanya sebesar $0,5 \%$ dipengaruhi oleh faktor lain yang tidak diteliti misalkan kesuburan tanah, iklim maupun faktor lain yang pengaruhnya tidak dapat diketahui secara pasti dan telah tercakup dalam faktor kesalahan.

b. Pengaruh Faktor-faktor Produksi Terhadap Hasil Produksi Janggelan

Pengaruh faktor-faktor produksi terhadap hasil produksi, dianalisis dengan melakukan uji $\mathrm{F}$ dan uji $\mathrm{t}$ terhadap 
persamaan model fungsi produksi yang telah diperoleh.

Adapun hasil dari uji tersebut adalah sebagai berikut :

1) $\mathrm{Uji} F$

Uji $\quad F$ dilakukan untuk mengetahui apakah semua variabel independent (tidak terikat) secara bersama-sama berpengaruh terhadap produksi janggelan. Uji $\mathrm{F}$ dilakukan pada taraf kepercayaan $95 \%$ atau nilai signifikansi 0,05 . Hasil dari uji $F$ disajikan pada Tabel 10. Tabel 10 menunjukkan bahwa nilai signifikansi sebesar 0,000, lebih kecil dari nilai signifikansi yang ditetapkan yang ditetapkan sebesar 0,05. Hal ini berarti bahwa penggunaan faktor-faktor produksi secara bersama-sama berpengaruh nyata terhadap produksi janggelan di Kecamatan Karangtengah.

2) Uji t

Uji $t$ dilakukan untuk mengetahui apakah pengaruh penggunaan faktor-faktor produksi secara individu atau masing-masing terhadap hasil produksi janggelan. Uji t dilakukan pada taraf kepercayaan 95\% atau nilai signifikansi 0,05 . Hasil dari uji t disajikan pada Tabel 11. Berdasarkan Tabel 11, diketahui bahwa diantara faktor-faktor produksi yang digunakan dalam usahatani janggelan, luas lahan, bibit, dan pupuk kandang merupakan faktor-faktor yang secara individu berpengaruh nyata terhadap produksi janggelan. Hal ini dilihat dari nilai signifikansi yang diujikan yaitu sebesar 0,05 . Sedangkan faktor produksi pupuk urea, pupuk phonska dan tenaga kerja tidak berpengaruh nyata secara individu dilihat dari nilai nilai signifikansi yang diujikan yaitu sebesar 0,05 .

c. Uji Asumsi Klasik

1) Uji Normalitas

Pengujian

normalitas

dilakukan dengan melihat normal probability plot yang membandingkan distribusi kumulatif dari data sesungguhnya dengan distribusi kumulatif dari data normal. Berdasarkan Gambar 1, menunjukkan distribusi normal, maka model regresi telah memenuhi asumsi normalitas.

Normal P-P Plot of Regression Standardized Residual

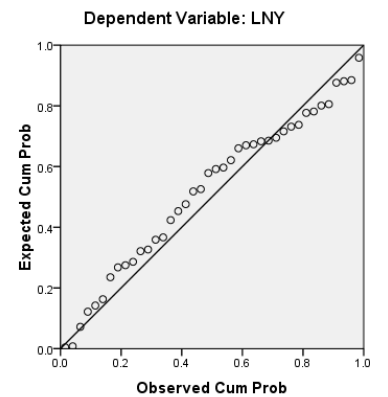

Gambar 1. Grafik normal probability plot

2) Uji Heteroskedastisitas

Berdasarkan gambar 2, diperoleh dari hasil analisis diagram scatterplot yang menyebar dan tidak membentuk pola tertentu, sehingga hasil analisis pada penelitian ini tidak terjadi heteroskedastisitas.

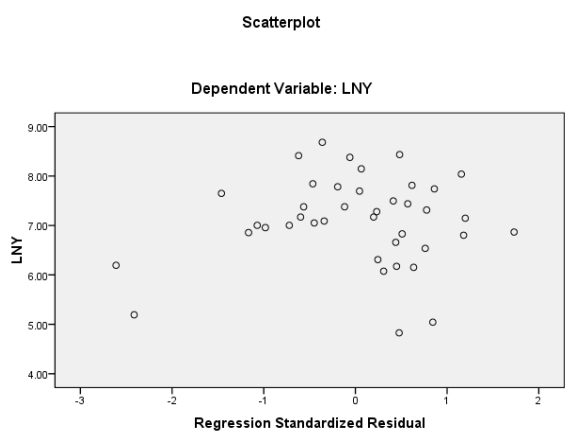

Gambar 2. Diagram Scatterplot

3) Uji Multikolinearitas

Berdasarkan Tabel 12, diketahui nilai $\mathrm{R}^{2}$ model utama ialah 0,995 dan nilai $\mathrm{R}^{2}$ dari masing-masing regresi parsial tidak ada yang lebih besar dari nilai regresi $\mathrm{R}^{2}$ model utama. Sehingga dalam analisis ini tidak terdapat multikolinearitas. 
Tabel 10. Analisis uji serentak penggunaan faktor produksi pada usahatani janggelan MT Juni 2015Mei 2016 di Kecamatan Karangtengah

\begin{tabular}{lcccccc}
\hline \multicolumn{1}{c}{ Model } & $\begin{array}{c}\sum \\
\text { kuadrat }\end{array}$ & $\mathrm{Df}$ & $\begin{array}{c}\text { Kuadrat } \\
\text { Tengah }\end{array}$ & $\begin{array}{c}\text { adjusted } \\
\mathrm{R}^{2}\end{array}$ & $\mathrm{~F}$ & $\mathrm{Sig}$ \\
\hline $\begin{array}{l}\text { Regression } \\
\text { Residual }\end{array}$ & 30,682 & 6 & 5,114 & 0,995 & 1.15 & 0.000 \\
\hline Total & 0,147 & 33 & 0,004 & 0,995 & & \\
\hline
\end{tabular}

Sumber : Analisis data primer.

Nilai signifikansi $\mathrm{F} 0,000<\alpha 0,05$ pada Tabel 10 berarti faktor produksi yang berupa luas lahan garapan, jumlah bibit, pupuk urea, pupuk phonska, pupuk kandang dan tenaga kerja secara bersama-sama berpengaruh nyata terhadap produksi janggelan di Kecamatan Karangtengah.

Tabel 11. Analisis uji keberartian koefisien regresi penggunaan faktor produksi pada usahatani janggelan MT Juni 2015-Mei 2016 di Kecamatan Karangtengah

\begin{tabular}{clccc}
\hline No. & \multicolumn{1}{c}{ Variabel } & Koefisien Regresi & $\mathrm{t}$ & Sig \\
\hline 1 & Luas lahan & $0,767^{* * * *}$ & 3,147 & 0.000 \\
2 & Bibit & $-0,162^{* *}$ & $-0,401$ & 0,019 \\
3 & Pupuk urea & $0,107^{\mathrm{ns}}$ & 2,077 & 0,294 \\
4 & Pupuk phonska & $0,001^{\mathrm{ns}}$ & 2,152 & 0,989 \\
5 & Pupuk kandang & $0,317^{* * * *}$ & $-0,469$ & 0,000 \\
6 & Tenaga kerja & $0,007^{\mathrm{ns}}$ & $-1,934$ & 0,943 \\
\hline
\end{tabular}

Sumber : Analisis data primer.

Keterangan :

$\left.{ }^{* * * *}\right) \quad$ : signifikan pada tingkat kepercayaan $99 \%$

**) : : signifikan pada tingkat kepercayaan $95 \%$

ns) : tidak signifikan pada tingkat kepercayaan 95\%

Pada variabel luas lahan yang tertera pada tabel 11 , nilai koefisien regresi tercatat 0,767 , hal ini menunjukkan bahwa jika luas lahan ditingkatkan atau diperluas sebesar 1 persen akan meningkatkan produksi janggelan sebanyak 0,767 persen. Sama hal nilai koefisien bibit dan pupuk kandang dengan nilai koefisien luas lahan, naik turun persentasi produksi janggelan disesuaikan dengan besar kecil dan positif negatif koefisiensi regresi masing-masing variabel.

Berbeda dengan ketiga variabel yang telah disebutkan, variabel pupuk urea, pupuk phonska, dan tenaga kerja tidak berpengaruh nyata terhadap produksi janggelan karena penggunaan variabel-variabel ini pada produksi janggelan di Karangtengah sudah melebihi batas maksimal (Law Of Diminishing Return). 
Tabel 12. Regresi parsial analisis faktor-faktor produksi pada usahatani janggelan MT Juni 2015-Mei 2016 di Kecamatan Karangtengah

\begin{tabular}{cc}
\hline Model & R Square \\
\hline X1-X2 & 0,977 \\
X1-X3 & 0,981 \\
X1-X4 & 0,976 \\
X1-X5 & 0,984 \\
X1-X6 & 0,813 \\
X2-X3 & 0,970 \\
X2-X4 & 0,967 \\
X2-X5 & 0,920 \\
X2-X6 & 0,896 \\
X3-X4 & 0,945 \\
X3-X5 & 0,974 \\
X3-X6 & 0,794 \\
X4-X5 & 0,938 \\
X4-X6 & 0,809 \\
X5-X6 & 0,772 \\
\hline R $^{2}$ MODEL UTAMA & 0,995 \\
\hline
\end{tabular}

Sumber : Analisis data primer.

Nilai $\mathrm{R}^{2}$ model utama ialah 0,995 dan nilai $\mathrm{R}^{2}$ dari masing-masing regresi parsial tidak ada yang lebih besar dari nilai regresi $\mathrm{R}^{2}$ model utama. Sehingga dalam analisis ini tidak terdapat multikolinearitas.

\section{KESIMPULAN DAN SARAN}

Kesimpulan dari penelitian ini adalah besarnya biaya mengusahakan yaitu $\mathrm{Rp}$. 12.048.982,20/Ha/MT, besarnya penerimaan yaitu Rp. 54.345.000/Ha/MT, besarnya pendapatan yaitu Rp. 42.296.017,80/Ha/MT.

Penggunaan faktor produksi luas lahan, jumlah bibit, pupuk urea, pupuk phonska, pupuk kandang, dan tenaga kerja secara bersama-sama berpengaruh nyata terhadap produksi janggelan. Faktor-faktor produksi yang secara individu berpengaruh nyata terhadap produksi janggelan adalah luas lahan, jumlah bibit dan penggunaan pupuk kandang.

Guna meningkatkan produksi janggelan di Kecamatan Karangtengah, petani dapat memaksimalkan faktor produksi yang mempunyai pengaruh signifikan terhadap produksi seperti luas lahan, jumlah bibit dan penggunaan pupuk kandang. Sedangkan faktor produksi yang kurang berpengaruh seperti pupuk urea, pupuk phonska dan tenaga kerja dapat disesuaikan penggunaannya.

\section{DAFTAR PUSTAKA}

Badan Pusat Statistik. 2013. Kabupaten Wonogiri dalam angka. BPS Provinsi Jawa Tengah

Badan Pusat Statistik. 2015 Luas areal dan produksi tanaman janggelan Di Kab. Wonogiri tahun 2009 - 2013. www.bpsjawatengah.com. Diakses pada tanggal 26 Nopember 2015.

Badan Pusat Statistik. 2015. Produksi perkebunan rakyat menurut kabupaten/kota di Jawa Tengah tahun 2014 (ton). www.bpsjawatengah.com. Diakses pada tanggal 23 Januari 2016.

Kadarsan.1992. Keuangan Pertanian dan Pembiayaan Perusahaan Agribisnis. PT. Gramedia Pustaka Utama. Jakarta.

Singarimbun, Masri. 1995. Metode Penelitian Survei. LP3S. Jakarta.

Soekartawi. 1991. Agribisnis, Teori dan Aplikasinya. Rajawali Press. Jakarta.

Surakhmad. 1994. Pengantar Penelitian Ilmiah. Penerbit Tarsito. Bandung.

Wulandari, 2015. Peranan PDRB Sub-Sektor Perkebunan Terhadap Pertumbuhan Ekonomi Di Kabupaten Bolaang Mongondow. Fakultas Pertanian Universitas Sam Ratulangi. Manado 